\title{
Earnings Forecast Optimism For U.S. Vs. Non-U.S. Firms
}

David Salerno, University of Scranton, USA

Nathan Jeppson, Montana State University, USA

\begin{abstract}
This study examines whether financial analysts are more optimistic in their earnings forecasts for non-U.S. firms than they are for U.S. firms. Several areas of research motivate this examination. First, research shows that global economic influences, such as economic downturns and the desire to increase the international content of portfolios, encourage investors to seek out international investment opportunities in new markets. Second, literature also reveals that emerging markets provide superior growth potential; however, analyzing such firms could introduce task complexity which research finds to be associated with lower forecast accuracy. Finally, research shows that financial analysts cover firms of which they have a favorable opinion. Therefore, because of this literature, it is reasonable to expect that analysts make more optimistic forecasts (over-estimate errors) of the earnings potential of the non-U.S. firms that they choose to follow vs. U.S. firms. Using a summary level measurement of forecast optimism, the authors find that analysts' forecasts are more optimistic for non-U.S. firms over both short and long-term horizons. In analyst-level tests, it was found that individual analysts produce more optimistic forecasts for non-U.S. firms in relation to their peers in the long-term; however, that optimism is reduced under short horizons. As portfolios become more internationally diversified, the result of this study will be useful to investors seeking analyst guidance about international investment opportunities.
\end{abstract}

Keywords: Analysts; Earnings Forecasts; Forecast Optimism; International Investment; Diversification

\section{INTRODUCTION}

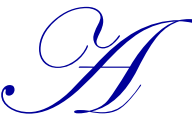

-nalysts' forecasts and recommendations could be thought of as information products that are supplied to the (capital) markets in response to a demand for investment advice. Although financial analyst optimism is well documented in the literature (Lin and McNichols, 1998; Dechow et al., 2000; Cowen et al., 2006) and anecdotally, investors often rely on this advice to make decisions. The tendency to overestimate good news and underestimate bad news (Easterwood and Nutt, 1999) and the choice of firms that they follow reveals the analysts' confidence in those firms' potential for growth. In fact, optimism among analysts is so entrenched that research on analysts' forecasts and recommendations show that analysts remain more likely to issue recommendations even after regulators' attempts to curb optimism (Barber et al., 2006). Moreover, selection bias suggests that analysts choose to follow firms for which they already hold favorable opinions (McNichols and O'Brien, 1997) and research also shows that this self-selection results from an analyst's desire to follow firms that they believe will enhance their commissions (Hayes, 1998). Because globalization, emerging foreign markets, and the desire to diversify portfolios cause investors to look for international investment opportunities (Lane and MilesiFerretti, 2008), it is reasonable to expect that analysts would look for growth opportunities in both established and emerging non-U.S. markets. Due to the aforementioned literature, the question arises whether analysts are more optimistic about the foreign firms that they choose to follow than they are about domestic firms. That question is the focus of this paper. Both aggregate level and individual analyst-level measurements of optimism were used. The aggregate level tests show that analysts' forecasts are more optimistic for non-U.S. firms under both short and longterm horizons. However, in the individual analyst-level tests, it was found that analysts produce more optimistic forecasts for non-U.S. firms in relation to their peers in the long-term, but less optimistic forecasts in the short-term. 
Sections of this paper provide a review of relevant prior literature and develop the hypotheses, a description of the methodology employed, the data sample, variable descriptions, test results, and a summary and concluding comments.

\section{PRIOR LITERATURE \& HYPOTHESIS DEVELOPMENT}

\subsection{Literature Review}

Prior studies have examined financial analysts' earnings forecast performance of international firms from several perspectives. Bae, Tan and Welker (2008) examine the effect of differences in accounting standards among countries and the effect of those differences on analyst following and analyst forecast accuracy. They find that larger differences in accounting standards are associated with lower analyst following and lower forecast accuracy. Bae, Stulz, and Tan (2008) study whether analysts are more accurate when forecasting earnings of firms in their home countries than they are when they analyze foreign firms. Results from their study show that local analysts are more accurate in countries where all three of the following conditions hold: 1) income smoothing is more prevalent, 2) firms disclose less information, and 3) stock returns are more a function of market level forces than firm level effects.

U.S. firms continue to become more internationally diversified (Herrmann et al., 2008) and research shows that analyst forecasts are more optimistic for internationally diversified firms (Duru and Reeb, 2002; Herrmann et al., 2008). Such optimism could occur when analysts attempt to gain favor with firms that they follow; Ke and Yu (2006) find that analysts' optimism may occur in order to establish favorable relationships with management.

In other research, using an international sample of firms, Hope (2003a) finds that enforcement of accounting standards improves forecast accuracy. Other studies of analysts' forecasts of foreign firms find that the level of accounting policy disclosure is associated with decreases in forecast dispersion and increases forecast accuracy (Hope, 2003b) and that forecast accuracy is positively associated with foreign firms that are cross-listed on US domestic stock exchanges (Lang et al., 2004). In an examination of whether analyst characteristics explain relative forecast errors across legal origins (common law versus civil law countries), Barniv et al. (2005) find that, for common-law countries, analysts with superior characteristics outperform other analysts. They find that this is due to the lower incentives that exist when investor protections are low. Their results reveal a link between legal and financial reporting environments with analysts' forecasts.

Other research finds that as U.S. domestic firms pursue geographic dispersion strategies, forecasts become more accurate and less optimistic, while becoming less accurate after cross-border integration (Mauri et al., 2013). However, prior literature does not examine differences in optimism that may exist between U.S. and non-U.S. firms. Rather than concentrating on U.S. domestic firms only, this paper differs from prior studies by examining differences in forecast optimism between U.S. and non-U.S. firms, regardless of whether they are internationally diversified or not. The study extends prior literature by examining optimism as a function of a firm's global home location.

\subsection{Hypothesis Development}

The literature provides several reasons to expect increased optimism for non-U.S. securities. For example, Detragiache et al. (2008) find that securities of foreign banks are more desirable because they can achieve improved economies of scale and better risk diversification than their domestic counterparts. Further, research regarding portfolio diversification encourages holding securities in all global markets (Kho et al., 2009). Currency risk is also a large factor in international investment selection. For instance, Krugman (2007) postulates there may be high risk in holding domestic currency.

With regard to emerging markets, research indicates that these markets provide investors with exceptional growth potential (Demirgüç-Kunt and Levine, 1996). Atsmon et al. (2012) examine the differences in growth rates between companies headquartered in developed economies in relation to companies based in emerging markets. They find that emerging market firms grew approximately twice as fast as those domiciled in developed economies. They also find that the rate of growth is two and a half times as fast for emerging market firms when both developed 
market and emerging market firms are competing in the same geographic area where neither company was headquartered. They give three reasons for this growth: 1) higher reinvestment rates: Emerging-market firms paid less in dividends than developed market firms, paying 39 percent of earnings in dividends compared to almost 80 percent by firms in developed economies. Emerging market firms also reinvest cash in fixed assets at an annual rate of 12 percent compared to 7 percent for developed-market companies; 2) agile asset reallocation: They find that emerging-market companies reallocate capital toward new business opportunities more at higher rates than do those firms headquartered in developed economies; and 3) growth-oriented business models: Atsmon et al. (2012) indicate that while firms in developed economies target smaller higher-margin segments and rely on brand recognition, firms in less developed economies provide lower-cost products to the fast-developing middle class around the world. Although these emerging markets have produced flat growth recently, analysts indicate that because markets, such as China, India, and Brazil, have large populations that are moving from rural areas to middle-class city life, and because the securities of these emerging market firms are low-priced, portfolios should include 25 percent investment in foreign emerging market funds (Ody, 2012).

Because the above literature indicates that analysts follow firms for which they have a favorable opinion (McNichols and O'Brien, 1997), because foreign securities could introduce complexity into the forecasting task which research finds to be associated with lower forecast accuracy (Clement, 1999), and because there is a welldocumented potential for growth of non-U.S.-based firms, it is expected that analysts issue more optimistic earnings forecasts for non-U.S. firms than they do for firms based in the U.S. This expectation was tested under both short and long-term horizons with the following hypotheses, stated in the alternate form:

H1: Analysts produce more optimistic earnings forecasts in the short-term for non-U.S. firms than they do for U.S. firms.

H2: Analysts produce more optimistic earnings forecasts in the long-term for non-U.S. firms than they do for U.S. firms.

\section{RESEARCH METHOD}

\subsection{Dependent Variables}

Forecast optimism - the dependent variable - is measured by using two methods. First, the authors used a summary model of the mean forecast error (BIAS) following prior literature (Duru and Reeb, 2002; Mauri et al., 2013) that measures optimism as the difference between the mean forecast made by all analysts following firm $\mathrm{j}$ in year $t$ and the actual earnings announced by that firm for the year, scaled by stock price and the beginning of year $t$;

$$
B I A S_{t j}=\frac{F O R E C A S T_{t j}^{t-1}-E A R N_{t j}}{P R I C E_{t-1, j}}
$$

where firm is designated by $\mathrm{j}$ and $\mathrm{t}$ denotes the fiscal year at the time of the earnings announcement date. FORECAST is computed as the mean of all analysts' forecasts of firm $j$ for year $t$ made at horizon $t-1$. EARN is the reported earnings of firm $\mathrm{j}$ for year $\mathrm{t}$. PRICE is the market stock price at the time of the forecast $(\mathrm{t}-1)$.

To further examine the effect of a firm's home country on forecast optimism, they repeat the tests using relative forecast optimism (RFOPT) as the dependent variable, as given by Cowen et al. (2006). RFOPT is an optimism specification that compares the individual analyst i's forecast of firm $j$ for year $t$ to the mean forecast of all analysts following the firm for that period, scaled by the standard deviation of the forecasts. Note that it does not include the actual announced earnings and, as such, is a measurement of how individual analysts are affected by the test variable in relation to other analysts;

$$
\operatorname{RFOPT}_{i t j}^{t-k}=\frac{\text { FORECAST }_{i t j}^{t-k}-\overline{\text { FORECAST }_{i t}^{t-k}}}{\operatorname{STDEV}\left(F O R E C A S T_{i t}^{t-k}\right)}
$$


where the individual analyst is given as $\mathrm{i}$, firm is designated by $\mathrm{j}, \mathrm{t}$ denotes the fiscal year at the time of the earnings announcement date, and $\mathrm{k}$ is the number of days that the forecast was made prior to the earnings announcement. FORECAST is analyst i's forecast of firm j's earnings for year $t$ made at horizon $t-k$. FORECAST is the mean forecast of firm j's earnings for time t made at horizon t-k. STDEV (FORECAST) is the standard deviation of the mean analyst forecast of firm j's earnings for time t made at horizon t-k.

\subsection{Independent Variables}

\subsubsection{Test Variable}

The test variable of interest is an indicator variable (LOC) which is coded as 1 for U.S. firms, zero otherwise. U.S. firms are defined as those that are domiciled in the United States and non-U.S. firms as those domiciled in all other countries, including Canada. Forecasts coded as U.S are collected from the U.S. I/B/E/S file and the firms coded as non-U.S. are collected from the International I/B/E/S file. ${ }^{1}$

\subsubsection{Control Variables}

Because industry differences could account for some variation in analysts forecast optimism, as in prior literature (Duru and Reeb, 2002; Bae, Tan and Welker, 2008) for both measures of optimism, the authors control for industry effects using the I/B/E/S SIG industry codes by including eleven indicator variables that control for the industry (IND) in which the firm operates. ${ }^{2}$ They also include the YEAR indicator variable for both measures of optimism to control for year effects.

For the BIAS measure of optimism, several controls that are used in extant literature (Duru and Reeb, 2002; Mauri et al., 2013) were used. Although they perform their tests on both a short-term and long-term sample, they control for horizon within each sample because different length forecast horizons could affect the results. For example, if for a given firm analysts made several forecasts over the prior year, with the earliest being 300 days prior to the firm's earnings announcement and the most recent being 60 days prior, the 300 day-old forecast would be included in the long-term dataset and the 60 day-old forecast would be included in the short-term sample. However, if another analyst's earliest (long-term) and most recent (short-term) forecasts in the past year were 200 days and 30 days, respectively, differences in horizon could affect the accuracy of the forecasts and thus affect optimism (because optimistic forecasts are essentially inaccurate over-estimates of earnings). Therefore, included was the HORIZ control, which is defined as the mean number of days between the issue of a forecast and the actual earnings announcement. Prior literature shows that horizon is positively associated with BIAS (Mauri, 2013); therefore, a positive coefficient on the HORIZ control is expected. The $\triangle \mathrm{EARN}$ variable is absolute value of the change in earnings per share from the previous year divided by the market stock price at the beginning of the year. Duru and Reeb (2002) find a positive association between $\triangle E A R N$ and BIAS; therefore, the same effect is expected. DISP is the standard deviation of analysts' earnings forecasts deflated by the market stock price on the forecast date. Because widely dispersed forecast values are thought to be an indication of task complexity (Duru and Reeb, 2002), DISP could have either a positive (Mauri et al., 2013) or negative (Duru and Reeb, 2002) effect on BIAS. Therefore, an expectation for its effect is not stated. The literature suggests that higher levels of analyst following are associated with less forecast optimism because such conditions result in more certain information environments (Duru and Reeb, 2002). Therefore, a control for the number of forecasts (NUMFOR), which is equal to the number of forecasts issued for the firm's earnings for the period, is added. Brown (2001) indicates that analysts make more optimistic forecasts in loss periods. Duru and Reeb (2002) point out that the managers of firms that report losses may also further understate net income in order to enable the reporting of higher profits in a future period - a practice known as taking a "big bath" (Elliott and Hanna, 1996; Moehrle 2002). As such, the indicator variable LOSS that is coded 1 if the firm reported a net loss in the period - zero otherwise - is included. It is anticipated that loss firms have a positive association with forecast optimism.

\footnotetext{
${ }^{1}$ Note that for the analysis, the country in which the analyst resides is not relevant; what matters is whether the company is a U.S. or non-U.S domiciled firm.

${ }^{2}$ SIG indicators include Finance (will serve as default), Health Care, Non-durable goods, Services, Durable Goods, Energy, Transportation, Technology, Basic Industries, Capital, and Utilities.
} 
For the tests of relative forecast optimism (RFOPT), the following controls are included. EXP is the number of years an analyst covered a particular firm. Cowen et al. (2006) suggests that experience could be negatively associated with optimism because analysts with more firm experience develop better information about the firm the longer they cover it and because better performing analysts (with less over-estimates) are more likely to survive in their jobs. However, Cowen et al. (2006) also explain that experience could be positively associated with optimism because as experienced analysts develop long-term relationships with management, the analysts may find it difficult to dispute management's projections, resulting in optimistic forecasts. Due to these reasons, no prediction is made of the effect that experience will have on RFOPT. ACCU is the absolute value of the difference between the individual analyst forecast and the average forecast of all analysts per firm $\mathrm{j}$ for the forecast period $\mathrm{t}$, divided by the forecast standard deviation. Prior literature shows that analysts who exhibit more accuracy in their prior forecasts will be less optimistic (Cowen et al., 2006). Therefore, the expectation is that ACCU will have a negative relationship with relative forecast optimism. HORIZ is the number of days between the issue of a forecast and the actual earnings announcement. Following prior literature (Cowen et al., 2006), longer horizons are expected to be associated with increased RFOPT.

\subsubsection{Models}

Regressions are performed using the two measurements for analyst's optimism described above; bias optimism (BIAS) and relative forecast optimism (RFOPT) as the dependent variable. The following model is used for the tests of BIAS optimism at the summary level:

BIAS $=\alpha+\beta_{1}$ LOC $+\beta_{2}$ LOSS $_{t j}+\beta_{3} \Delta$ EARN $_{t j}+\beta_{4}$ HORIZ $_{t j}+\beta_{5}$ NUMFOR $_{t j}+\beta_{6}$ IISP $_{t j}+\beta_{7}$ IND $_{t j}+\beta_{8}$ YEAR

where firm is designated by $\mathrm{j}$ and $\mathrm{t}$ denotes the fiscal year at the time of the earnings announcement date. All variables in the model are described above.

Also examined is the effect of LOC on the differences in earnings forecasts between the individual analyst and the consensus of all other analysts making earnings forecasts for the same firm and year. The following model is used for the test of relative forecast optimism at the individual analyst level:

RFOPT $=\alpha+\beta_{1} \mathrm{LOC}+\beta_{2}$ HORIZ $_{\mathrm{itj}}+\beta_{3} \mathrm{EXP}_{\mathrm{itj}}+\beta_{4} \mathrm{ACCU}_{\mathrm{itj}}+\beta_{5} \mathrm{IND}_{\mathrm{tj}}+\beta_{6} \mathrm{YEAR}$

where the individual analyst is designated by i. All variables in the model are described above.

The tests are conducted by using OLS to regress each of the two optimism measurements on the location of the firm (LOC) and controls. A significant coefficient on LOC suggests that location of the firm being forecast explains, at least in part, the optimistic nature of the forecast. A positive sign on the LOC coefficient would indicate that optimism is higher for non-US firms.

\subsubsection{Sample Data and Descriptive Statistics}

Data are collected from the Institutional Brokers Estimate System (I/B/E/S) database for the period 2002 to 2012. Firm-year observations with missing values are omitted. Because the study includes short and long-term analysis, two datasets are developed from the sample. As described above, the short-term dataset includes 720,674 observations for the most recent forecasts for the earnings announcement of firm $\mathrm{j}$ for year $\mathrm{t}$; the long-term dataset includes 718,661 observations for the earliest forecasts in the prior twelve months for the earnings announcement of firm $\mathrm{j}$ for year $\mathrm{t}$. Table 1 Panel A provides descriptive statistics for the long-term sample. 
Table 1: Descriptive Statistics for the Period from 2002-2012

\begin{tabular}{|c|c|c|c|c|c|c|c|c|c|c|}
\hline \multicolumn{4}{|c|}{$\begin{array}{c}\text { Panel A: Descriptive Statistics-Sample w } \\
\text { Variable }\end{array}$} & \multicolumn{3}{|c|}{ Mean } & \multicolumn{2}{|l|}{ Median } & \multicolumn{2}{|c|}{ Standard Deviation } \\
\hline \multicolumn{4}{|c|}{ BIAS } & \multicolumn{3}{|c|}{0.261} & \multicolumn{2}{|l|}{0.000} & \multicolumn{2}{|c|}{0.138} \\
\hline \multicolumn{4}{|l|}{ RFOPT } & \multicolumn{3}{|c|}{0.054} & \multicolumn{2}{|l|}{0.057} & \multicolumn{2}{|l|}{1.075} \\
\hline \multicolumn{4}{|l|}{ LOC } & \multicolumn{3}{|c|}{0.704} & \multicolumn{2}{|l|}{1.000} & \multicolumn{2}{|l|}{0.456} \\
\hline \multicolumn{4}{|l|}{ LOSS } & \multicolumn{3}{|c|}{0.111} & 0.000 & & \multicolumn{2}{|l|}{0.314} \\
\hline$\triangle \mathrm{EARN}$ & & & & & 0.064 & & 0.015 & & 0.185 & \\
\hline HORIZ & & & & & 273.0 & & 310.0 & & 102.6 & \\
\hline NUMFOR & & & & & 63.79 & & 48.00 & & 55.23 & \\
\hline DISP & & & & & 0.037 & & 0.008 & & 0.131 & \\
\hline EXP & & & & & 4.247 & & 4.000 & & 2.648 & \\
\hline ACCU & & & & & 0.877 & & 0.749 & & 0.653 & \\
\hline Panel B: D & scriptiv & Statistics- & imple w & Most R & cent Forec & ts (Short & Term), $n=72$ & 674 & & \\
\hline & Vari & ble & & & Mean & & Median & & ndard De & iation \\
\hline BIAS & & & & & 0.026 & & 0.000 & & 0.139 & \\
\hline RFOPT & & & & & -0.070 & & -0.092 & & 0.945 & \\
\hline LOC & & & & & 0.705 & & 1.000 & & 0.456 & \\
\hline LOSS & & & & & 0.112 & & 0.000 & & 0.315 & \\
\hline$\Delta \mathrm{EARN}$ & & & & & 0.064 & & 0.015 & & 0.187 & \\
\hline HORIZ & & & & & 119.7 & & 97.00 & & 98.38 & \\
\hline NUMFOR & & & & & 63.71 & & 48.00 & & 55.22 & \\
\hline DISP & & & & & 0.039 & & 0.009 & & 0.140 & \\
\hline EXP & & & & & 4.245 & & 4.000 & & 2.648 & \\
\hline ACCU & & & & & 0.782 & & 0.697 & & 0.565 & \\
\hline Panel C: S & earman & earson C & relation & Sample & vith Earlie & Forecast & (Long-Term & & & \\
\hline Variable & BIAS & RFOPT & LOC & LOSS & $\Delta$ EARN & HORIZ & NUMFOR & DISP & EXP & ACCU \\
\hline BIAS & --- & 0.098 & -0.019 & 0.377 & 0.430 & 0.027 & -0.040 & 0.660 & -0.033 & $-0.001 \dagger$ \\
\hline RFOPT & 0.257 & --- & 0.027 & 0.105 & 0.025 & 0.046 & -0.021 & 0.058 & -0.016 & 0.059 \\
\hline LOC & 0.044 & 0.021 & --- & -0.086 & -0.039 & -0.123 & -0.096 & -0.009 & -0.155 & -0.082 \\
\hline LOSS & 0.303 & 0.113 & -0.086 & --- & 0.353 & 0.018 & -0.099 & 0.339 & -0.045 & 0.018 \\
\hline$\Delta \mathrm{EARN}$ & 0.004 & $0.003 * *$ & 0.005 & 0.331 & --- & 0.004 & -0.058 & 0.591 & -0.027 & 0.009 \\
\hline HORIZ & 0.013 & 0.050 & -0.165 & 0.022 & $-0.00 \dagger$ & --- & 0.157 & 0.016 & 0.261 & 0.157 \\
\hline NUMFOR & -0.054 & -0.016 & -0.115 & -0.114 & -0.043 & 0.201 & --- & -0.042 & 0.166 & 0.052 \\
\hline DISP & 0.276 & 0.136 & 0.138 & 0.369 & 0.551 & 0.006 & 0.002 & --- & -0.036 & -0.015 \\
\hline EXP & -0.060 & -0.010 & -0.148 & -0.039 & -0.032 & 0.291 & 0.208 & -0.069 & --- & 0.046 \\
\hline ACCU & 0.013 & 0.065 & -0.086 & 0.028 & 0.059 & 0.174 & -0.029 & $-0.001 \uparrow$ & 0.052 & --- \\
\hline Panel D: S & earman & earson C & relation & Sample & vith Most & ecent Fort & asts (Short- & rm) & & \\
\hline Variable & BIAS & RFOPT & LOC & LOSS & $\triangle$ EARN & HORIZ & NUMFOR & DISP & EXP & $\mathrm{ACCU}$ \\
\hline BIAS & --- & -0.120 & -0.019 & 0.376 & 0.429 & 0.020 & -0.040 & 0.699 & -0.034 & 0.054 \\
\hline RFOPT & 0.356 & --- & -0.031 & -0.103 & -0.019 & 0.082 & 0.004 & -0.064 & 0.004 & -0.077 \\
\hline LOC & 0.044 & -0.039 & --- & -0.085 & -0.039 & 0.055 & -0.096 & -0.009 & -0.155 & -0.025 \\
\hline LOSS & 0.305 & -0.105 & -0.085 & --- & 0.351 & 0.013 & -0.100 & 0.343 & -0.046 & 0.035 \\
\hline$\triangle \mathrm{EARN}$ & 0.005 & 0.015 & 0.005 & 0.331 & --- & 0.009 & -0.059 & 0.588 & -0.027 & 0.020 \\
\hline HORIZ & 0.006 & 0.077 & 0.030 & 0.019 & -0.019 & --- & -0.128 & 0.020 & -0.205 & -0.030 \\
\hline NUMFOR & -0.054 & 0.010 & -0.114 & -0.116 & -0.044 & -0.157 & --- & -0.047 & 0.167 & -0.009 \\
\hline DISP & 0.301 & -0.167 & 0.144 & 0.389 & 0.563 & -0.021 & -0.026 & --- & -0.039 & 0.017 \\
\hline EXP & -0.060 & 0.006 & -0.161 & -0.040 & -0.032 & -0.206 & 0.208 & -0.079 & --- & 0.012 \\
\hline $\mathrm{ACCU}$ & 0.061 & -0.096 & -0.044 & 0.037 & 0.059 & -0.068 & -0.006 & 0.041 & 0.018 & --- \\
\hline
\end{tabular}

Spearman correlations are on the bottom left of the diagonal; Pearson correlations are on the top right. **Indicates significance at the 5 percent level; $\uparrow$ indicates no significance; all other correlations are significant at the 1 percent level. Variable definitions: BIAS is actual forecast optimism, as defined in Section 3.1. RFOPT is relative forecast optimism, as defined in Section 3.1. LOC is an indicator variable set to 1 if the forecast is for a U.S. domestic firm - else zero. LOSS is an indicator variable coded 1 for firms with a loss in the current period - else zero. $\triangle E A R N$ is the absolute value of the change in earnings per share from the previous year divided by the market stock price at the beginning of the year. HORIZ is the mean number of days between the issue of a forecast and the actual earnings announcement. NUMFOR is the number of forecasts made by analysts for the earnings of firm $\mathrm{j}$ for year $\mathrm{t}$. DISP is the standard deviation of analysts' earnings forecasts deflated by the market stock price on the forecast date. EXP is the number of years and analyst covered an announcement. ACCU is the absolute value of the difference between the individual analyst forecast and the average forecast of all analysts per firm $\mathrm{j}$ for the forecast period $\mathrm{t}$, divided by the forecast standard deviation. 
The mean value for BIAS is 0.261 . The positive sign indicates that overall forecasts were optimistic. Likewise, RFOPT has a mean of 0.054 , indicating that that the average individual analysts forecast is greater than the consensus forecast for the same firm and year. LOC and LOSS are indicator variables. For LOC, the mean of 0.704 and median of 1.000 indicates that there are slightly more non-U.S. firms than U.S. firms in the long-term dataset. For LOSS, the mean of 0.111 and median of 0.000 indicates that there are more firms in the dataset that broke even or earned a profit during the period than there were firms that experienced a loss. $\triangle E A R N$ has a mean of 0.064 and a median of 0.015 , and horizon has mean of 273 days with a median of 310 days, both of which are consistent with prior studies (Duru and Reeb, 2002). NUMFOR is the number of forecasts made for a particular firm and year. The mean number of forecasts made is 63.79. The mean value of DISP (0.037) is consistent with prior literature (Mauri et al., 2013). The average number of years of experience for an analyst in the data set is 4.247. Panel B presents the descriptive statistics for the short-term dataset. The values are similar to and consistent with the values in Panel A with one notable exception. For RFOPT, the mean (-0.070) and median (-0.092) are negative.

Panel C of Table 1 provides the Pearson and Spearman correlations for the long-term (earliest) forecast dataset. Pearson correlations are above the diagonal and the Spearman correlations are below. The correlation between BIAS and RFOPT is positive (0.098) for Pearson and for Spearman (0.257). The variable of interest (LOC) is negatively correlated with BIAS for Pearson (-0.019) and for Spearman (0.044). LOC is also positively correlated with RFOPT for Pearson (0.027) and Spearman (0.021). Overall, the correlations in Panel C are consistent with expectations and with prior literature. Panel D in Table 1 provides the Pearson and Spearman correlations for the short-term (most recent) forecast dataset. Pearson correlations are above the diagonal and the Spearman correlations are below. Results are similar to the long-term dataset with two notable exceptions. First, for Pearson RFOPT is negatively correlated with BIAS (-0.120) and second, for Spearman, LOC is negatively correlated with RFOPT $(-0.039)$. These differences are likely due to the effect that longer vs. shorter forecast horizons have on relative forecast optimism.

\section{RESULTS}

The analysis was performed using the two dependent variables described above: BIAS is a measurement of the overall optimism of all analysts in relation to the actual earnings of the firms being followed and RFOPT is a measurement of the degree to which individual analysts over estimate earnings of a firm in relation to all other analysts following that firm. Table 2 gives the results of BIAS regressions.

The first column shows the expected coefficient sign and the next two columns give the results of the shortterm and long-term tests, respectively. Note that LOC is positive and significant for both short-term $(0.012, \mathrm{p}<.05)$ and long-term $(.012, \mathrm{p}<.05)$. Recall that a positive sign on the LOC coefficient indicates that analysts' optimism is increased for the non-U.S. firms that they follow. This result provides evidence in support of both $\mathrm{H} 1$ and $\mathrm{H} 2 .^{3}$ The controls LOSS, $\triangle \mathrm{EARN}$, and HORIZ are all significant with positive coefficients. These results are consistent with prior literature (Duru and Reeb, 2002) and indicate that losses (LOSS), large changes in earnings from the prior period $(\triangle \mathrm{EARN})$, and longer durations between the forecast and earnings announcement (HORIZ) are associated with increased optimism. NUMFOR is not significant in either test. As described above, the DISP control is a proxy for uncertainty and lack of consensus among analysts (Duru and Reeb, 2002). Note that it is negative and significant for the short-term test and positive and significant $(0.139, \mathrm{p}<.01)$ for the long-term dataset. Prior literature also finds conflicting results for DISP (Duru and Reeb, 2002; Mauri et al., 2013). Overall, Table 2 results show that financial analysts are more optimistic about non-U.S. firms in both the short-term and long-term datasets and provide evidence in support of both $\mathrm{H} 1$ and $\mathrm{H} 2$.

\footnotetext{
${ }^{3}$ Sensitivity of the results was checked by also estimating the model without industry controls with both measures of optimism. Similar results were obtained and it was concluded that the results are not sensitive to industry controls.
} 
Table 2: Bias Forecast Optimism (BIAS)

\begin{tabular}{|c|c|c|c|}
\hline Independent Variables $^{1}$ & Predicted Sign & Short-Term $^{2}$ & Long-Term $^{2}$ \\
\hline \multirow[t]{2}{*}{ Intercept } & & 0.394 & 0.377 \\
\hline & & $(2.90) * * *$ & $(3.08) * * *$ \\
\hline \multirow[t]{2}{*}{ LOC } & + & 0.012 & 0.012 \\
\hline & & $(2.05)^{* *}$ & $(2.12)^{* *}$ \\
\hline \multirow[t]{2}{*}{ LOSS } & + & 0.145 & 0.121 \\
\hline & & $(21.82)^{* * *}$ & $(18.38)^{* * *}$ \\
\hline \multirow[t]{2}{*}{$\triangle \mathrm{EARN}$} & + & 0.216 & 0.162 \\
\hline & & $(61.84) * * *$ & $(25.59) * * *$ \\
\hline \multirow[t]{2}{*}{ HORIZ $^{3}$} & + & 0.086 & 0.117 \\
\hline & & $(3.27)^{* * *}$ & $(4.87) * * *$ \\
\hline \multirow[t]{2}{*}{ NUMFOR $^{3}$} & - & 0.113 & 0.035 \\
\hline & & $(1.09)$ & $(0.41)$ \\
\hline \multirow[t]{2}{*}{ DISP } & $+/-$ & -0.000 & 0.139 \\
\hline & & $(-3.63) * * *$ & $(9.61)^{* * *}$ \\
\hline Industry controls & & Included & Included \\
\hline Year-by-year controls & & Included & Included \\
\hline \# of observations & & 15,179 & 10,450 \\
\hline Adjusted $\mathrm{R}^{2}$ & & 0.263 & 0.250 \\
\hline
\end{tabular}

t-Statistic in parentheses. ${ }^{* * *}, * *, *$ Indicates significance at the 1 percent, 5 percent and 10 percent levels respectively. ${ }^{1}$ Continuous variables (including dependent variable) have been winsorized at the $1 \%$ and $99 \%$ levels to ensure results are not sensitive to extreme observations. ${ }^{2}$ Short term is defined as the most recent forecast before earnings release announcements. Long term is defined as the earliest forecast available during the current fiscal year. ${ }^{3}$ Values for this variable have been multiplied by one thousand for ease of interpretation. Variable definitions: BIAS is actual forecast optimism, as defined in Section 3.1. LOC is an indicator variable set to 1 if the forecast is for a U.S. domestic firm - else zero. LOSS is an indicator variable coded 1 for firms with a loss in the current period - else zero. $\triangle \mathrm{EARN}$ is the absolute value of the change in earnings per share from the previous year divided by the market stock price at the beginning of the year. HORIZ is the mean number of days between the issue of a forecast and the actual earnings announcement. NUMFOR is the number of forecasts made by analysts for the earnings of firm $\mathrm{j}$ for year t. DISP is the standard deviation of analysts' earnings forecasts deflated by the market stock price on the forecast date.

Table 3 provides the results of regressions using RFOPT as the dependent variable. The first column shows the expected coefficient sign and the next two columns give the results of the short-term and long-term tests, respectively. LOC is significant in both short-term $(-0.054, \mathrm{p}<.01)$ and long-term $(0.063, \mathrm{p}<.01)$ tests. The results for long-term RFOPT are consistent with those of the long-term BIAS tests and provide additional evidence for H2. The short-term coefficient is negative $(-0.054, \mathrm{p}<.01)$, indicating that for the most recent forecasts, in relation to their peers, analysts make less over-estimates for non-U.S. firms than they do for US firms. However, this result does not necessarily contradict the BIAS results. Literature shows that forecasts become more accurate as earnings announcements near (Jacob et al., 1999). The BIAS result suggests that overall analysts make more overestimates in the short-term about non-U.S. firms, while the RFOPT results show that those forecasts are closer relative to each other. Consistent with Cowen et al. (2006), HORIZ is positive and significant for both the shortterm $(0.791, p<.01)$ and long-term $(0.478, p<.01)$ tests indicating that as horizon increases, relative forecast optimism also increases. ${ }^{4}$ EXP is positive and significant for the short-term test $(0.005, \mathrm{p}<.01)$ and negative and significant $(-0.009, \mathrm{p}<.01)$ for the long-term test. Recall that no prediction was made regarding the direction that the EXP coefficient would take on because the literature provides support for either outcome. The results for the EXP control indicate that, in the short-term, more experienced analysts have greater levels of confidence in the firms that they choose to follow. ACCU is negative and significant $(-0.123, \mathrm{p}<.01)$ for the short-term tests. This result is consistent with prior literature discussed above (Cowen et al., 2006) which finds that more accurate analysts are also less optimistic in their forecasts. However, in the long-term tests, the coefficient on ACCU is positive $(0.092, \mathrm{p}<$ .01 ), indicating that analysts who have a history of accuracy appear to be more optimistic. The difference in signs may be due to the effects of horizon as numerous studies find that analysts are less accurate over longer horizons (Jacob et al., 1999; Cowen et al., 2006; Bae, Tan and Welker, 2008). The results in Table 3 indicate that individual analysts' forecasts tend to coalesce in the short-term and provide additional support for $\mathrm{H} 2$, indicating that analysts' produce more optimistic earnings forecasts for non-U.S. firms in relation to their peers under long horizons than they do for U.S.-based firms.

\footnotetext{
${ }^{4}$ Values for this variable have been multiplied by one thousand for ease of interpretation 
Table 3: Relative Forecast Optimism (RFOPT)

\begin{tabular}{|l|c|c|c|}
\hline \multicolumn{1}{|c|}{ Independent Variables $^{1}$} & Predicted Sign & Short-Term $^{2}$ & Long-Term $^{2}$ \\
\hline Intercept & & -0.071 & -0.018 \\
\hline LOC & & $(-0.38)$ & $(-0.08)$ \\
\hline & + & -0.054 & 0.063 \\
\hline HORIZ & & $(-21.03)^{* * *}$ & $(21.43)^{* * *}$ \\
\hline & + & 0.791 & 0.478 \\
\hline EXP & $+/-$ & $(69.02)^{* * *}$ & $(36.79)^{* * *}$ \\
\hline & & 0.005 & -0.009 \\
\hline ACCU & - & $(11.21)^{* * *}$ & $(-18.20)^{* * *}$ \\
\hline & & -0.123 & 0.092 \\
\hline Industry Controls & & $(-63.32)^{* * *}$ & $(46.71)^{* * *}$ \\
\hline Year-by-year controls & & Included & Included \\
\hline \# of observations & & Included & Included \\
\hline Adjusted ${ }^{2}$ & & 720,674 & 718,661 \\
\hline
\end{tabular}

t-Statistic in parentheses. ${ }^{* * *}, * *, *$ Indicates significance at the 1 percent, 5 percent and 10 percent levels respectively. ${ }^{1}$ Continuous variables (including dependent variable) have been winsorized at the $1 \%$ and $99 \%$ levels to ensure results are not sensitive to extreme observations. ${ }^{2}$ Short term is defined as the most recent forecast before earnings release announcements. Long term is defined as the earliest forecast available during the current fiscal year. ${ }^{3}$ Values for this variable have been multiplied by one thousand for ease of interpretation.Variable definitions: RFOPT is relative forecast optimism, as defined in Section 3.1. LOC is an indicator variable set to 1 if the forecast is for a U.S. domestic firm - else zero. HORIZ is the mean number of days between the issue of a forecast and the actual earnings announcement. EXP is the number of years and analyst covered an announcement. ACCU is the absolute value of the difference between the individual analyst forecast and the average forecast of all analysts per firm $\mathrm{j}$ for the forecast period $\mathrm{t}$, divided by the forecast standard deviation.

\section{CONCLUSION}

As investors look for international opportunities, financial analysts search for firms that have the potential for growth. Because non-U.S. firms present superior investing opportunities and because analysts could be expected to follow firms that they anticipate will perform well, it is hypothesized that analysts are more optimistic in their earnings forecasts for non-U.S. firms than they are for U.S. firms. Measurements of both overall optimism and individual analysts relative forecast optimism were used and tests for both long and short-term horizons were performed. It was found that analysts' forecasts overall are more optimistic for non-U.S. firms at the aggregate level. In tests of relative forecast optimism, it was found that individual analysts produce more optimistic forecasts for non-U.S. firms in relation to their peers in the long run. However, relative forecast optimism is reduced under short horizons likely because as earnings announcements near, analysts' forecasts converge and are therefore less optimistic in relation to each other. Because this study focuses on internationally diversified portfolios, the results will be useful to investors seeking analyst guidance about non-U.S. investment opportunities.

\section{AUTHOR INFORMATION}

Dr. David Salerno received his Ph.D. degree from Kent State University-Kent. He is currently an assistant professor of accounting in the Kania School of Management at the University of Scranton, Scranton, PA. His research interests include earnings quality, analysts' forecasts, and executive compensation. E-mail: david.salerno@scranton.edu

Dr. Nathan Jeppson received his Ph.D. degree from Kent State University-Kent. He is currently an assistant professor of accounting in the Jake Jabs College of Business and Entrepreneurship at Montana State UniversityBozeman. His research interests include analysts' forecasts and earnings management. E-mail: nathan.jeppson@montana.edu (Corresponding author)

\section{REFERENCES}

1. Atsmon, Y., Kloss, M., Smit, S., \& Matson, E. (2012). Parsing the Growth Advantage of Emerging- Market Companies. Mckinsey Quarterly, (3) 10-14. Retrieved from: http://www.mckinsey.com/insights 
2. Bae, K., Stulz, R., \& Tan, H. (2008). Do Local Analysts Know More? A Cross-Country Study of the Performance of Local Analysts and Foreign Analysts. Journal of Financial Economics, 88(3) 581-606.

3. Bae, K., Tan, H., \& Welker, M. (2008). International GAAP Differences: The Impact on Foreign Analysts. The Accounting Review, 83(3) 593-628.

4. Barber, B., Lehavy, R., McNichols, M., \& Trueman, B. (2006). Buys, Holds, and Sells: The Distribution of Investment Banks' Stock Rating and the Implications for the Profitability of Analysts' Recommendations. Journal of Accounting \& Economics, 41(1) 87-117.

5. Barniv, R., Myring, M., \& Thomas, W. (2005). The Association Between the Legal and Financial Reporting Environments and Forecast Performance of Individual Analysts. Contemporary Accounting Research, 22(4) 727-758.

6. Brown, L. D., (2001). A Temporal Analysis of Earnings Surprises: Profits Versus Losses. Journal of Accounting Research, 39(2) 221-242.

7. Clement, M. B. (1999). Analyst Forecast Accuracy: Do Ability, Resources, and Portfolio Complexity Matter? Journal of Accounting \& Economics, 27(3) 285-303.

8. Cowen, A., Groysberg, B., \& Healy, P. (2006). Which Types of Analyst Firms Are More Optimistic? Journal of Accounting \& Economics, 41(1/2) 119-146.

9. Dechow, P. M., Hutton, A. P., \& Sloan, R. G. (2000). The Relation Between Analysts' Forecasts of LongTerm Earnings Growth and Stock Price Performance Following Equity Offerings. Contemporary Accounting Research, 17(1) 1-32.

10. Demirgüç-Kunt, A., \& Levine, R. (1996). Stock Markets, Corporate Finance, and Economic Growth: An Overwiew. The World Bank Economic Review, 10(2) 223-239.

11. Detragiache, E., Tressel, T., \& Gupta, P. (2008). Foreign Banks in Poor Countries: Theory and Evidence. The Journal of Finance, 63(5) 2123-2160.

12. Duru, A., \& Reeb, D. M. (2002). International Diversification and Analysts' Forecast Accuracy and Bias. Accounting Review, 77(2) 415-433.

13. Easterwood, J., \& Nutt, S. (1999). Inefficiency In Analysts' Earnings Forecasts: Systematic Misreaction or Systematic Optimism. Journal of Finance, 54(5) 1777-1797.

14. Elliott, J.A., \& Hanna, J. D. (1996). Repeated Accounting Write-offs and the Information Content of Earnings. Journal of Accounting Research, 34(Supplement): 135-155.

15. Hayes, R. M. (1998). The Impact of Trading Commission Incentives on Analysts' Stock Coverage Decisions and Earnings Forecasts. Journal of Accounting Research, 36(2) 299-320.

16. Herrmann, D. R., Hope, O., \& Thomas, W. B. (2008). International Diversification and Forecast Optimism: The Effects of Reg FD. Accounting Horizons, 22(2) 179-197.

17. Hope, O. (2003a). Disclosure Practices, Enforcement of Accounting Standards, and Analysts' Forecast Accuracy: An International Study. Journal of Accounting Research, 41(2) 235-272.

18. Hope, O. (2003b). Accounting Policy Disclosures and Analysts' Forecasts. Contemporary Accounting Research, 20(2) 295-321.

19. Jacob, J., Lys, T. Z., \& Neale, M. A. (1999). Expertise in Forecasting Performance of Security Analysts. Journal of Accounting \& Economics, 28(1) 51-82.

20. Ke, B., \& Yu, Y. (2006). The Effect of Issuing Biased Earnings Forecasts on Analysts' Access to Management and Survival. Journal of Accounting Research, 44(5) 965-999.

21. Kho, B., Stulz, R. M., \& Warnock, F. E. (2009). Financial Globalization, Governance, and the Evolution of the Home Bias. Journal Of Accounting Research, 47(2) 597-635.

22. Krugman, P. (2007). Will There Be a Dollar Crisis? Economic Policy, 22(51) 435-467.

23. Lane, P., \& Milesi-Ferretti, G. (2008). The Drivers of Financial Globalization. American Economic Review, 98(2) 327-332.

24. Lang, M., Lins, K., \& Miller, D. (2004). Concentrated Control, Analyst Following, and Valuation: Do Analysts Matter Most When Investors Are Protected Least? Journal of Accounting Research, 42(3) 589-623.

25. Lin, H., \& McNichols, M. (1998). Underwriting Relationships, Analysts' Earnings Forecasts and Investment Recommendations. Journal of Accounting and Economics, 25(1) 101-127.

26. Mauri, A. J., Lin, J., \& Neiva De Figueiredo, J. (2013). The Influence of Strategic Patterns of Internationalization on the Accuracy and Bias of Earnings Forecasts by Financial Analysts. International Business Review, 22(4) 725-735. Retrieved from: http://www.sciencedirect.com/science/journal/09695931 
27. McNichols, M., \& O'Brien, P. (1997). Self-Selection and Analyst Coverage. Journal of Accounting Research, 35(3) 167-199.

28. Moehrle, S. R. (2002). Do Firms Use Restructuring Charge Reversals to Meet Earnings Targets? Accounting Review, 77(2) 397-413.

29. Ody, E. (2012). Emerging Markets: Ready to Rally. Kiplinger's Personal Finance, 66(12) 23-26. 
NOTES 